\title{
Reducing bycatch in coral reef trap fisheries: escape gaps as a step towards sustainability
}

\author{
Ayana Elizabeth Johnson* \\ Center for Marine Biodiversity and Conservation, Scripps Institution of Oceanography, University of California, \\ San Diego, 9500 Gilman Drive, La Jolla, California 92083-0202, USA
}

\begin{abstract}
Widespread use of minimally selective fish traps has contributed to the overfishing of Caribbean coral reefs. Traps typically target high-value fish such as groupers (Serranidae and Epinephelidae) and snappers (Lutjanidae), but they also have high bycatch of ecologically important herbivores (parrotfish (Scaridae) and surgeonfish (Acanthuridae)) and non-target species. One strategy for reducing this bycatch is to retrofit traps with rectangular escape gaps that allow juveniles and narrow-bodied species to escape; yet the effectiveness of these gaps has not been thoroughly tested. On the shallow reefs of Curaçao, Netherlands Antilles, I compared the catch of traditional Antillean chevron traps (the control) to the catch of traps with short escape gaps $(20 \times 2.5 \mathrm{~cm})$, traps with tall escape gaps $(40 \times 2.5 \mathrm{~cm})$, and traps with a panel of large aperture mesh. With data from 19024 -h trap sets, the mean number of fish caught was 11.84 in control traps, 4.88 in short gap traps, 4.43 in tall gap traps, and 0.34 in large mesh traps. Compared to controls, traps with short or tall gaps caught significantly fewer bycatch fish (-74 and $-80 \%$ respectively), key herbivores $(-58$ and $-50 \%$ respectively), and butterflyfish (Chaetodontidae; -90 and $-98 \%$ respectively). The mean length of captured fish was significantly greater in gap traps because juveniles were able to escape via the gaps. Escape gaps reduce neither the catch of high-value fish, nor the total market value of the catch. Therefore, using escape gaps could make trap fishing more sustainable without reducing fishermen's revenues.
\end{abstract}

KEY WORDS: Fish traps · Bycatch · Escape gaps · Parrotfish · Caribbean · Coral reef fisheries · Gear-based fisheries management $\cdot$ Artisanal fisheries

\section{INTRODUCTION}

Catch of coral reef fish even at an artisanal scale can lead to severe overfishing (Jackson 1997, Hawkins \& Roberts 2004). Management efforts to prevent this are complicated by the multi-species and multi-gear nature of reef fisheries. Gear-based fisheries management, an approach that exploits differences between gear types in order to indirectly control catch composition (McClanahan \& Mangi 2004, McClanahan \& Cinner 2008), can increase fishery selectivity, and thereby sustainability. Within this context, the present study focuses on fish traps, which are both responsible for the majority of reef fish captured in the Caribbean and around the world (Gobert 1998, Mahon \& Hunte 2001), and known for high levels of bycatch (Stewart 2007).
Bycatch, defined as discarded plus incidental fish catch (Alverson et al. 1994), hinders fishery sustainability by accelerating the depletion of fish stocks. Although discard rates are typically low in artisanal fisheries (Hawkins et al. 2007), incidental catch of juveniles and non-target species is still a great concern. Fish traps usually retain most fish that enter, resulting in high catch biodiversity (Munro 1983) and high bycatch of juvenile fish and non-target species (often $>50 \%$ of the catch; Ferry \& Kohler 1987), leading to overexploitation of reef fish populations even with relatively low effort (Hardt 2008).

Research on trap catch composition (i.e. quantity, size distribution, and species diversity) and the factors affecting it has been conducted for several decades. Beginning with Munro's comprehensive work in 
Jamaica in the 1970s, researchers have examined the influences of soak time, trap shape, bait, habitat type, conspecific attraction, lunar phase, and local level of exploitation (e.g. Munro et al. 1971, Munro 1974, Ferry \& Kohler 1987, Dalzell \& Aini 1992, Wolff et al. 1999, Robichaud et al. 2000, Garrison et al. 2004). However, research on the management of trap fisheries has focused almost exclusively on the use of larger mesh sizes to reduce the catch of juveniles (e.g. Bohnsack et al. 1989, Robichaud \& Hunte 1997, Sary et al. 1997, Stewart 2007). One drawback of this approach is that, given the diversity of fish caught with traps, it is impossible to select one mesh size that optimizes the yield of all exploited species (Mahon \& Hunte 2001). An alternative modification to fish traps, the inclusion of escape gaps that allow juveniles and narrow-bodied species to exit, is a promising method of bycatch reduction that deserves further investigation.

Munro et al. (2003) tested escape gaps (largest gap size $9.0 \times 3.3 \mathrm{~cm}$ ) in double-arrowhead-shaped traps (an experimental trap design not used by fishermen), and showed that gaps reduce both catch quantity and catch mass relative to controls. Inspired by Curaçao's proposed regulation to require escape gaps in all traps, I employed typical Antillean traps to build upon Munro's work. Here I provide family composition, quantity, length, mass and value data for the catch of 4 types of fish traps, then consider the ecological and economic implications of requiring escape gaps use, and directly compare escape gap and mesh size management options.

\section{MATERIALS AND METHODS}

Study sites. From May through August 2008, I experimentally fished with 4 types of fish traps at 3 sites on the northwest coast of Curaçao, Netherlands Antilles (all near $12^{\circ} 19^{\prime} \mathrm{N}, 69^{\circ} 09^{\prime} \mathrm{W}$ ): Lagún, Santa Marta, and Westpunt. All 3 locations are fringing reefs where a light level of fishing (several small boats a day) is occurring. The benthic habitats of the sites differ somewhat in terms of rugosity, reef slope, and species composition, thereby increasing the generality of the experimental results.

Fish biomass on Curaçao's shallow reefs is considered high relative to many other locations in the Caribbean (Sandin et al. 2008), but low in comparison to protected areas on the Mesoamerican Barrier Reef and Cuba (Newman et al. 2006). Traps account for almost $60 \%$ of Curaçao's reef fish landings by weight (Dilrosun 2002), and the trap fishery is currently unregulated.

Trap design. Control traps were tested against traps retrofitted with one of 3 experimental treatments:
1 panel of large-aperture mesh, 2 short $(20 \times 2.5 \mathrm{~cm})$ escape gaps, or 2 tall $(40 \times 2.5 \mathrm{~cm})$ escape gaps (Fig. 1). All traps were handmade by a local fisherman in the traditional Antillean chevron shape. Traps differed slightly in exact dimensions, but all trap volumes were $\sim 0.50 \mathrm{~m}^{3}$. Tree-branches formed the frames, and galvanized '1-inch' wire mesh (hexagonal mesh, aperture 2.7 high by $3.5 \mathrm{~cm}$ wide) was attached to all sides of the traps with bailing wire. The entrances were downcurving, tapering cylinders with a horse neck shape. One side panel of each trap was affixed to the frame using cable ties so that it could be used as a door. Escape gaps were constructed from $0.8 \mathrm{~cm}$ diameter steel reinforcement bars ('rebar') that were bent, welded, and secured to the traps with cable ties.

I selected the aperture of the large mesh (hexagonal mesh, aperture $5 \times 8 \mathrm{~cm}$ ) based on research that recommended a minimum aperture of $5.1 \mathrm{~cm}$ in order to optimize catch for consumption (Mahon \& Hunte 2001). Large mesh was only used for one panel of the large mesh traps so as to maintain the visual image (a concern in trap studies such as Robichaud et al. 1999) and the structural integrity of the traps (a concern of fishermen). Visual image refers to how visible the traps are, which is relevant because fish can be attracted to structure.

Experimental design. The experiment employed a randomized block design. At each site, I set 8 traps $(2$ of each type) in reef habitat at 12 to $15 \mathrm{~m}$ depth at
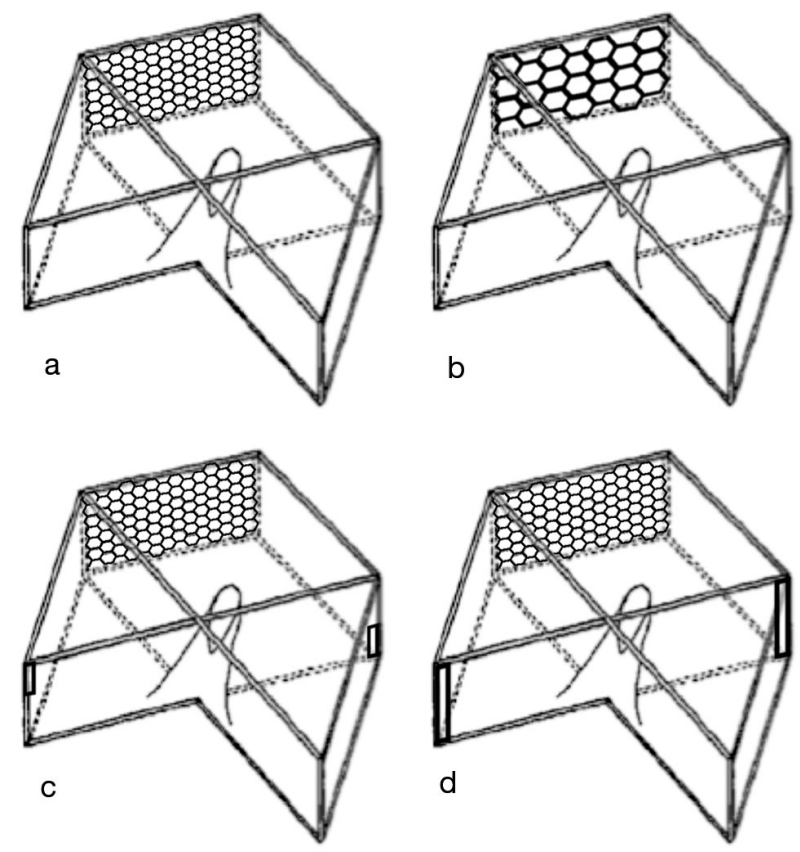

Fig. 1. The 4 types of fish traps used in this experiment: (a) control (traditional Antillean arrowhead trap), and traps with (b) 1 large mesh panel, (c) 2 short $(20 \times 2.5 \mathrm{~cm})$ escape gaps, and (d) 2 tall $(40 \times 2.5 \mathrm{~cm})$ escape gaps. (Adapted from image in Munro et al. 1971) 
marked locations $25 \mathrm{~m}$ apart. Each week, I closed the doors of the traps using cable ties and left the traps submerged for $24 \mathrm{~h}$ following the common practice of Curaçaoan fishermen. I refer to this 24 -h soak time as a trap set. Traps were not baited, as previous studies have shown that bait does not influence trap effectiveness (e.g. Munro et al. 1971). Using SCUBA, I checked trap contents and recorded the species, fork length, and condition of each fish. I then cut the cable ties securing the doors of the traps to release the trapped fish, and left the doors in the open position until the start of the next week of the experiment. To mitigate the potential problem of differential catch between trap locations within a site, all traps were randomly reshuffled amongst the marked locations every week.

Length to weight conversions. To convert fish fork length $(L)$ in centimeters into weight $(W)$ in grams, I employed the standard allometric relationship: $W=$ $\mathrm{a} L$ '. Values for the constants ' $a$ ' and ' $b$ ' were obtained for each species from FishBase (Froese \& Pauly 2009), using congeners if necessary. Where multiple 'a' and ' $b$ ' values were available for a species, I selected values from Caribbean studies with the largest sample sizes. As the present study focuses broadly on trap fishing effects, I pooled data to the family level for analysis.

Fish categorizations and market value. I assigned families of captured fish to one of 4 market value categories: (1) high-value fish, (2) key herbivores, (3) sochi (the Papiamentu term for a mixed-species group of reef fish that are sold collectively at one price), or (4) bycatch (see Table 1 for categorizations). I obtained fish prices by interviewing 8 fish vendors, and asking them to estimate the prices at which they had pur- chased various fish from fishermen in the past several months. Their responses were consistent and are presented in Table 1. Groupers (Epinephelidae) refers only to Cephalopholis cruentata (graysby) and C. fulva (coney) as no other grouper species were captured. Parrotfish (Scaridae) and surgeonfish (Acanthuridae) are often sold as sochi, but for this analysis are placed in a separate 'key herbivores' category. Fish for which all vendors reported zero market value were categorized as bycatch. Fish in the bycatch category are discarded at sea, given away as food, or occasionally used as bait. Moray eels (Muraenidae) were included only in the family level analyses because their weight and length mask, without changing the direction of, treatment effects. Also, morays are sold very infrequently, and therefore have little effect on catch value. For calculation of catch values, fish that were dead or in poor condition, and therefore not saleable, were assigned a market value of zero. Fish considered to be in poor condition were those that had major visible damage (e.g. severe scratches or bite marks) or were no longer actively swimming.

Data analyses. I present data for number of fish caught and catch value at the trap level, data for length at the individual fish level, and for mass at both the fish and trap levels. I compared these variables across the 4 trap types and 3 sites using 2-way ANOVAs, treating both trap type and study site as fixed effects. Note that including trap set date as an additional fixed factor in a 3-way ANOVA with each of the main catch metrics (quantity, length, mass, and value) as response variables revealed no significant effects of date on catch, and, thus, set date is subsequently ignored. With 1-way ANOVAs and Bonferroni corrections for multi-

Table 1. Mean market value, included families, primary importance, and potential effects of removal from the ecosystem, for the 4 fish market value categories. Prices are given in US dollars. Importance is within the context of the present study

\begin{tabular}{|c|c|c|c|c|}
\hline Category & $\begin{array}{l}\text { Mean market } \\
\text { value }\left(\mathrm{kg}^{-1}\right)\end{array}$ & $\begin{array}{l}\text { Families } \\
\text { included }\end{array}$ & $\begin{array}{l}\text { Primary } \\
\text { importance }\end{array}$ & $\begin{array}{l}\text { Potential effects } \\
\text { of removal }\end{array}$ \\
\hline High-value fish & $\$ 5.85$ & $\begin{array}{l}\text { Lutjanidae (snappers) } \\
\text { Epinephelidae (groupers) }\end{array}$ & Most valuable catch & Reduced income for fishermen \\
\hline Key herbivores & $\$ 2.94$ & $\begin{array}{l}\text { Acanthuridae (surgeonfish) } \\
\text { Scaridae (parrotfish) }\end{array}$ & Eat algae & Increased algal dominance \\
\hline Sochi & $\$ 3.15$ & $\begin{array}{l}\text { Balistidae (triggerfish) } \\
\text { Haemulidae (grunts) } \\
\text { Holocentridae (squirrelfish) } \\
\text { Labridae (wrasses) } \\
\text { Mullidae (goatfish) } \\
\text { Pomacanthidae (angelfish) }\end{array}$ & Biodiversity & $\begin{array}{l}\text { Reduced diversity and } \\
\text { associated interactions }\end{array}$ \\
\hline Bycatch & $\$ 0.00$ & $\begin{array}{l}\text { Bothidae (flounders) } \\
\text { Chaetodontidae (butterflyfish) } \\
\text { Monacanthidae (filefish) } \\
\text { Ostraciidae (trunkfish) } \\
\text { Pomacentridae (damselfish) }\end{array}$ & & \\
\hline
\end{tabular}


ple comparisons, I compared the catches of fish $<10 \mathrm{~cm}$, of each of the commonly caught families, and of each of the fish market value categories. For significant ANOVA models, I used Tukey-Kramer pairwise comparisons to identify differences in catch between the control and each experimental trap type. Where $>1$ experimental trap type differed from the control, the minimum Tukey-Kramer q-value is given. All reported errors are standard errors. To account for potential effects of any undetected spatial and temporal autocorrelation, I present clustered (i.e robust) standard errors. This approach is analogous to including a random effects term in a standard ANOVA.

\section{RESULTS}

Over the course of the experiment, 190 traps were set and 1028 fish were captured. Although catch varied across fished sites (see Table 2 for details of effect of location), it did not affect the relative difference of treatment effects and is thus not discussed further.

\section{Diversity of catch}

I captured 44 species from 19 families. Twenty-seven species from 6 families made up $84 \%$ of the catch, with clear differences in catch composition between trap types (Fig. 2). When compared directly with each other, there were no significant differences between the catches of short and tall gap traps at the family level. Compared with controls, traps with either short

Table 2. Results of ANOVAs testing for significant differences between trap types and research sites. ${ }^{*} \mathrm{p}<0.05,{ }^{* *} \mathrm{p}<0.01$, ${ }^{* * *} \mathrm{p}<0.0001$

\begin{tabular}{|lcc|}
\hline & $F$ & df \\
\hline Mean number & & \\
Trap type & $26.41^{* * *}$ & 3 \\
Site & $12.86^{* * *}$ & 2 \\
Trap type $\times$ site & $3.12^{* *}$ & 6 \\
Mean length (cm) & & \\
Trap type & $15.78^{* * *}$ & 3 \\
Site & 1.63 & 2 \\
Trap type $\times$ site & $2.92^{* *}$ & 6 \\
Mean mass $(\mathbf{k g})$ & & \\
Trap type & $13.76^{* * *}$ & 3 \\
Site & $8.61^{* *}$ & 2 \\
Trap type $\times$ site & $2.32^{*}$ & 6 \\
Mean value (USD) & & \\
Trap type & $6.91^{* *}$ & 3 \\
Site & $5.93^{* *}$ & 2 \\
Trap type $\times$ site & 1.77 & 6 \\
\hline
\end{tabular}

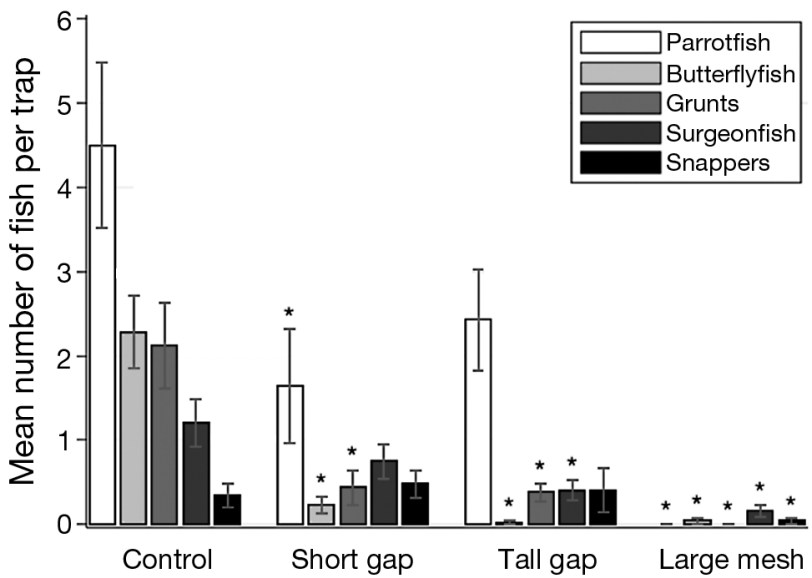

Fig. 2. Mean $( \pm \mathrm{SE})$ catch composition of trap sets for families representing $5 \%$ or more of the total catch of control traps. Significant differences from controls are indicated; ${ }^{*} \mathrm{p}<0.05$

or tall gaps caught significantly fewer grunts (Haemulidae, $F_{3,186}=11.7, \mathrm{p}<0.001$; Tukey-Kramer minimum $\mathrm{q}=5.48, \mathrm{p}<0.001$ ) and butterflyfish (Chaetodontidae, $\left.F_{3,186}=20.52, \mathrm{p}<0.001 ; \mathrm{q}=8.88, \mathrm{p}<0.001\right)$, and tall gap traps also reduced the catch of surgeonfish $\left(F_{3,186}=\right.$ 5.80, $\mathrm{p}<0.001 ; \mathrm{q}=4.08, \mathrm{p}<0.025$; Fig. 2). Of all the captured families, butterflyfish displayed the most dramatic catch declines: $-90 \%$ with short gaps and -98\% with tall gaps compared to a control mean of 2.28 butterflyfish per trap set. Parrotfish comprised the greatest proportion of the catch in all trap types (except for large mesh traps, which caught no parrotfish), although short gap traps did catch $63 \%$ fewer parrotfish than the control mean of 4.5 per trap set $\left(F_{3,186}=\right.$ 8.11, $\mathrm{p}<0.001 ; \mathrm{q}=4.31, \mathrm{p}<0.01$ ). Scarus taeniopterus (princess parrotfish) and Sparisoma aurofrenatum (redband parrotfish) represented the majority of captured scarids. Moray eels were present in $22 \%$ of the trap sets, and the number of morays captured is significantly lower only for the large mesh relative to the control $\left(F_{3,186}=3.25, \mathrm{p}=0.023 ; \mathrm{q}=4.09, \mathrm{p}<0.025\right.$; Fig. 2). Importantly, the catch of snappers (Lutjanidae, a prime target of trap fishermen) was not significantly different across trap types.

\section{Quantity of catch}

Quantity of catch per trap set was significantly lower in all modified trap types (short gap, tall gap, and large mesh) relative to the control mean of 11.84 fish (Table 2, Fig. 3a). Large mesh traps caught only 17 fish over the entire experiment, and over two-thirds of trap sets in this treatment caught zero fish. On average, large mesh traps caught 0.34 fish per trap set, a difference of $-97.1 \%$ relative to control traps. Because of 

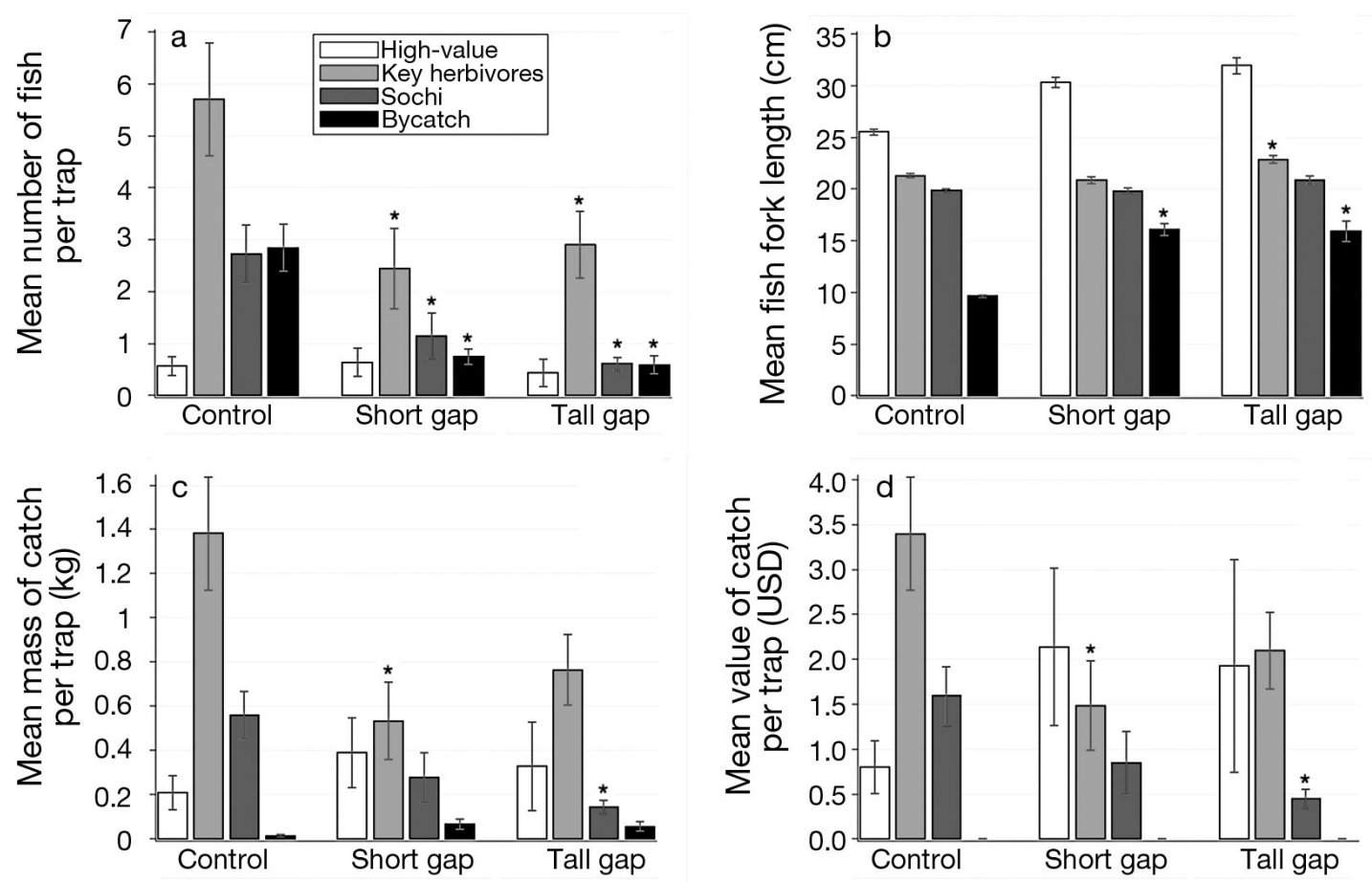

Fig. 3. Mean ( \pm SE) (a) number, (b) length, (c) mass, and (d) market value of catch per trap set by fish market value categories. Catch value data only include saleable fish. Significant differences from controls are indicated; ${ }^{*} \mathrm{p}<0.05$

this extremely low catch, results for this trap type are excluded from Fig. 3. Short and tall escape gap traps respectively caught means of 4.88 and 4.43 fish per trap set, differences of -59 and $-63 \%$ relative to control traps. Key herbivores were the largest component of catch in all trap types, representing $48 \%$ of the fish caught in control traps, $47 \%$ in large mesh, $49 \%$ in short gap, and $64 \%$ in tall gap traps; although both gap heights did significantly reduce the quantity of key herbivores captured $\left(F_{3,186}=9.82, \mathrm{p}<0.0001\right.$; $\mathrm{q}=3.77$, $\mathrm{p}<0.025$; Fig. 3a). Both gap heights also significantly reduced the quantity of sochi $\left(F_{3,186}=9.85, \mathrm{p}<0.0001\right.$; $\mathrm{q}=4.36, \mathrm{p}<0.01)$ and bycatch $\left(F_{3,186}=22.83, \mathrm{p}<\right.$ $0.0001 ; \mathrm{q}=8.18, \mathrm{p}<0.001$ ) captured (Fig. 3a). The mean catch quantities for short and tall gaps respectively were 2.40 and 2.83 key herbivores per trap set (differences of -58 and $-50 \%$ relative to controls), 1.13 and 0.60 sochi fish per trap set $(-59$ and $-78 \%$ relative to controls), and 0.73 and 0.57 bycatch fish per trap set ( -74 and $-80 \%$ relative to controls). Notably, there were no significant differences between trap types in the quantity of high-value fish captured.

\section{Length of catch}

The mean length of fish retained in traps with escape gaps was significantly greater than that of fish in control traps (Table 3, Fig. 3b). Compared to controls, short and tall gap traps both caught significantly fewer fish $<10 \mathrm{~cm}$ in fork length $\left(F_{3,186}=20.36, \mathrm{p}<0.0001 ; \mathrm{q}=\right.$ $6.82, \mathrm{p}<0.025)$. The mean lengths of fish caught in short and tall gap traps were 21.11 and $22.59 \mathrm{~cm}$ respectively, differences of +13 and $+19 \%$ relative to fish in control traps. The mean length of fish in large mesh traps was not significantly different from the control mean. When examined by value categories, the mean length of bycatch fish was greater in both the short and tall gap traps $\left(F_{3,200}=12.80, \mathrm{p}<0.0001 ; \mathrm{q}=\right.$ $6.07, \mathrm{p}<0.001)$, the mean length of key herbivores was greater in tall gap traps $\left(F_{3,523}=4.33, \mathrm{p}=0.005 ; \mathrm{q}=\right.$ $3.94, \mathrm{p}<0.025)$, and the mean length of sochi and highvalue fish remained unchanged across trap types (Fig. 3b). Mean length of bycatch fish, which are often narrow-bodied and therefore likely to escape via the gaps, was 16.07 and $15.94 \mathrm{~cm}$ in short gap and tall gap traps respectively, differences of approximately $+65 \%$ relative to fish caught in control traps.

\section{Biomass of catch}

The mean mass of an individual captured fish was $228 \pm 10.4 \mathrm{~g}$ for control traps, $276 \pm 18.8 \mathrm{~g}$ for short gaps, $293 \pm 23.4 \mathrm{~g}$ (significantly longer than controls) for tall gaps, and $401 \pm 103.6 \mathrm{~g}$ for large mesh traps $\left(F_{3,891}=\right.$ $4.81, \mathrm{p}<0.01 ; \mathrm{q}=3.98, \mathrm{p}<0.025)$. The mean total mass per trap set was significantly lower in short gap and 
Table 3. Data for number, mass, and value of fish captured per trap set, and data for fork length per fish. Means, SE, sample sizes (n), and percent difference from control are presented for each trap type. Overall percent differences and differences for each site (Lagún $=\mathrm{L}$, Santa Marta $=\mathrm{S}$, and Westpunt $=\mathrm{W}$ ) are presented. Means significantly different from control are indicated; ${ }^{*} \mathrm{p}<0.05,{ }^{* *} \mathrm{p}<0.01,{ }^{* * *} \mathrm{p}<0.0001$

\begin{tabular}{|c|c|c|c|c|}
\hline & \multirow{2}{*}{ Mean \pm SE } & \multirow{2}{*}{$\mathrm{n}$} & \multicolumn{2}{|c|}{ Difference (\%) } \\
\hline & & & Overall (\%) & Per site $(\mathrm{L}, \mathrm{S}, \mathrm{W})$ \\
\hline \multicolumn{5}{|c|}{ Mean number } \\
\hline Control & & 50 & & \\
\hline Short gap & $11.84 \pm 1.92$ & 48 & -58.9 & $(-37.7,-47.2,-91.6)$ \\
\hline Tall gap & $4.88 \pm 1.91^{* * *}$ & 42 & -62.6 & $(-44.1,-61.7,-78.4)$ \\
\hline Large mesh & $\begin{array}{l}4.43 \pm 1.81^{* * *} \\
0.34 \pm 1.92^{* * *}\end{array}$ & 50 & -97.1 & $(-95.8,-97.9,-97.6)$ \\
\hline \multicolumn{5}{|c|}{ Mean length (cm) } \\
\hline Control & & 591 & & \\
\hline Short gap & $18.37 \pm 0.45$ & 234 & +14.9 & $(+12.5,+20.0,+0.4)$ \\
\hline Tall gap & $21.11 \pm 0.97^{* *}$ & 186 & +23.0 & $(+19.9,+21.8,+31.1)$ \\
\hline Large mesh & $\begin{array}{l}22.59 \pm 0.88^{* * *} \\
21.03 \pm 3.06\end{array}$ & 17 & +14.5 & $(+5.2,+49.7,+0.7)$ \\
\hline \multicolumn{5}{|c|}{ Mean mass (kg) } \\
\hline Control & & 50 & & \\
\hline Short gap & $2.17 \pm 0.36$ & 48 & -41.5 & $(-10.1,-24.0,-90.8)$ \\
\hline Tall gap & $1.27 \pm 0.45^{*}$ & 42 & -38.2 & $(-26.7,-39.6,-52.5)$ \\
\hline Large mesh & $\begin{array}{l}1.34 \pm 0.37 \\
0.12 \pm 0.36^{* * *}\end{array}$ & 50 & -94.5 & $(-93.6,-92.2,-97.2)$ \\
\hline \multicolumn{5}{|c|}{ Mean value (USD) } \\
\hline Control & $5.77 \pm 1.00$ & 50 & & \\
\hline Short gap & $4.47 \pm 1.57$ & 48 & -22.5 & $(+34.3,-9.8,-92.2)$ \\
\hline Tall gap & $4.59 \pm 1.44$ & 42 & -20.5 & $(-25.0,-12.5,-28.6)$ \\
\hline Large mesh & $0.52 \pm 1.03^{* * *}$ & 50 & -91.0 & $(-92.2,-83.4,-96.7)$ \\
\hline
\end{tabular}

large mesh traps relative to controls (Table 3, Fig. 3c). Key herbivores dominated the mass of trap catches, representing $64 \%$ of the mass in controls, $42 \%$ in short gap, and $59 \%$ in tall gap traps. There were no significant differences between the masses of high-value fish or bycatch fish captured by gap and control traps, but relative to controls, the mass of key herbivores was lower in short gap traps $\left(F_{3,186}=10.56, \mathrm{p}<0.0001 ; \mathrm{q}=\right.$ $4.89, \mathrm{p}<0.005)$, and the mass of sochi was lower in tall gap traps $\left(F_{3,186}=7.75, \mathrm{p}<0.001 ; \mathrm{q}=4.91, \mathrm{p}<0.005\right.$; Fig. 3c). However, when short and tall gaps are compared directly with each other, there were no significant differences in the mass of key herbivores $(\mathrm{q}=1.27$, $p>0.1)$ or sochi $(q=1.57, p>0.1)$ caught.

\section{Market value of catch}

There were no significant differences in overall catch value between gap and control traps (Table 3), but there were differences at the level of market value categories (Fig. 3d). The value of key herbivores in traps with short gaps was $\$ 1.49$ US, a difference of $-56 \%$ relative to control traps $\left(F_{3,186}=9.29, \mathrm{p}<0.0001\right.$; $\mathrm{q}=4.29, \mathrm{p}<0.01$ ), and the value of sochi in traps with tall gaps was $\$ 0.45$ US, a difference of $-71 \%$ relative to control traps $\left(F_{3,186}=6.18, \mathrm{p}<0.001 ; \mathrm{q}=4.29, \mathrm{p}<0.01\right)$. However, when short and tall gap traps were compared directly to each other, there were no significant differences in the values of key herbivores $(\mathrm{q}=1.29$, $p>0.1$ ) or sochi $(q=1.49, p>0.1)$ caught. Most notably, the value of the high-value fish targeted by fishermen was not significantly different between gap and control traps. Of captured fish, $4 \%$ (and $7 \%$ of captured parrotfish) were dead or in poor condition and therefore not included in the value calculations. The mean catch value of large mesh traps was significantly lower than that of controls at only \$0.52 US per trap set.

\section{DISCUSSION}

Escape gaps significantly reduce the bycatch of traditional Antillean fish traps while maintaining overall catch value (Fig. 3), and as such represent an important opportunity for increasing the sustainability of trap fisheries. This is in contrast with large mesh, which greatly reduces catch value while reducing bycatch. Despite the fact that gap traps resulted in a $\sim 60 \%$ decrease in number of fish captured, mass of catch only dropped by $\sim 40 \%$ because the length of the catch in gap traps was $\sim 20 \%$ greater (Table 3 ). The 
catch of surgeonfish, butterflyfish, and fish $<10 \mathrm{~cm}$ was significantly lower in both the short and tall gap traps, implying that narrow-bodied and/or small fish that enter traps can locate the gaps and escape (Fig. 2). Parrotfish dominated catches in the control and gap traps, both numerically and in terms of biomass. Compared to parrotfish, high-value groupers and snappers represented a much smaller proportion of the catch quantity in control and gap traps, but were still an important component of catch value, and the per trap set value of high-value fish did not differ between trap types.

The difference in effectiveness of the 2 gap sizes appears to be nominal as catch composition in the short and tall gap traps was very similar. The significant differences were that, relative to control traps, only tall gaps increased the mean length of key herbivores, only short gaps reduced the mean mass and value of key herbivores, and only tall gaps reduced the mean mass and value of sochi. However, when short and tall gap traps are compared directly to each other, these mass and value differences are not significant. Thus, specific gap height appears to be much less important than whether or not a gap is used. The fisheries department of Curaçao has proposed the required use of short $(20 \times 2.5 \mathrm{~cm})$ escape gaps in all fish traps. The choice of short versus tall gaps there could have minor consequences for trap catch composition, but should not affect catch values.

Although this experiment was conducted on a single island, in a single season, at a single depth, and is therefore only a snapshot of the potential effectiveness of escape gaps, the general finding that some of the smaller, less marketable fish escape would likely apply to most trap fisheries. The specifics of how gaps would change trap catch composition and value elsewhere depend on location-specific fish population demographics and definitions of bycatch. Short of repeating this experiment in other areas where trap fishing is occurring, it could be informative to re-calculate the potential effects of gaps on catch value using locationspecific fish market values.

The minimal cost of retrofitting Antillean traps $(<\$ 1$ US per trap) and the undiminished catch value are especially important attributes of escape gaps given the already tenuous profitability of some trap fisheries (Mangi et al. 2007). Escape gaps can be constructed from a diversity of materials, and gap dimensions can be tailored to retain specific target species. This is in contrast with the traditional approach of regulating trap fisheries by mesh size, which can increase selectivity but simultaneously render traps unprofitable. Mesh size retrofits are costly and a hexagonal mesh aperture tall enough to let out a butterflyfish would also be wide enough to let out a market-sized snapper. Other studies have observed similarly large (80 to
$95 \%$ ) catch reductions resulting from increased mesh size, with target species representing a great portion of those declines (e.g. Bohnsack et al. 1989, Robichaud et al. 1999, Mahon \& Hunte 2001). This reduction may be due to lack of a 'live bait effect': though small fish in gap traps may eventually escape, the time they spend in the trap can attract larger fish. The apertures in large mesh traps can be too large to retain small fish long enough to produce this effect. However, mesh size restrictions might be a viable regulatory approach where fish populations are less depleted. The fact that $5 \mathrm{~cm}$ mesh traps catch so few fish can be considered a measure of the degradation of Caribbean reef fish populations (Knowlton \& Jackson 2008).

Trap use in reef habitats is globally widespread, making it worthwhile to consider the potential ramifications of a broad adoption of escape gaps. As traps with tall gaps catch a mean 7.4 fewer fish (including a mean 2.9 fewer key herbivores) than control traps, it follows that retrofitting the $\sim 100$ actively used traps on Curaçao could reduce bycatch there by tens of thousands of fish annually. Considering there are more than 20000 active fish traps in Puerto Rico and the United States Virgin Islands alone (Sheridan et al. 2003), use of escape gaps throughout the Caribbean has the potential to reduce bycatch and herbivore catch by millions of fish annually.

In the last half-century, Caribbean trap catch composition has shifted from carnivore (snapper and grouper) to herbivore (parrotfish and surgeonfish) dominance (Garrison et al. 1998), yet another example of 'fishing down food webs' (Pauly et al. 1998). Parrotfish and surgeonfish, formerly considered undesirable (Zaneveld 1961), are now commonly being marketed in Curaçao and are increasingly available in supermarkets and restaurants in the United States (author's pers. obs.). This is of particular concern because parrotfish have become the principal grazers on Caribbean reefs since the regional die-off of the sea urchin Diadema antillarum in 1983 (Lessios et al. 1984), and because large parrotfish, which are retained in traps, consume disproportionately more algae per fish than their smaller congeners (Bruggemann et al. 1996).

Gear-based management has been touted as a way to account for this increased importance of herbivores in supporting the resilience of a coral-dominated benthos, and as a means to adaptively manage reef fisheries in the context of climate change (McClanahan et al. 2008, Cinner et al. 2009). Of all the types of fishing gear commonly used on reefs, traps catch the greatest proportion of herbivores (McClanahan et al. 2008); it is therefore important to manage their use, and escape gaps could help to reduce herbivore mortality.

Apart from high herbivore catch, fish traps have additional detrimental effects on reefs that cannot be 
mitigated by escape gaps. First, they can cause physical damage to benthic habitats when they are set, hauled, lost or abandoned (Chiappone et al. 2002, Sheridan et al. 2003, Mangi \& Roberts 2006). Also, traps catch moray eels, which likely serve an important but often underappreciated predatory role in coral reef ecosystems, especially in areas where large groupers and snappers have been overfished (Gilbert et al. 2005). Further, escape gaps do not reduce catch of wide-bodied bycatch fish (such as trunkfish (Ostraciidae), and scorpionfish (Scorpaenidae)), nor do they allow escape of the large fish that are disproportionately important to reproductive potential (Birkeland \& Dayton 2005). Last, escape gaps do not eliminate the issue of fish being injured and dying in the traps, and thus becoming unmarketable. While escape gaps are a very effective bycatch reduction tool, it is unlikely that any amount of tinkering with trap design will sufficiently ameliorate these concerns. Additionally, gear modifications such as escape gaps can be less effective in practice because fishermen may use the gear differently than researchers, and without enforcement compliance can be low (Cox et al. 2007). Hence, from an ecosystem perspective, additional restrictions on trap fishing are warranted.

Nevertheless, escape gaps could create long-term benefits that are at least 3-fold. First, reduced catch of key herbivores could promote healthier reefs via increased algal grazing (Burkepile \& Hay 2008). Second, reduced catch of juveniles could result in a greater number of reproductively mature fish, thereby increasing population productivity. Third, reduced catch of bycatch fish could increase biodiversity, and thereby tourist interest, since many recreational divers consider species diversity a key attraction of coral reef dives (Parsons \& Thur 2008). Escape gaps have great potential to benefit both fishermen and conservation, and requiring escape gaps in all reef environments where traps are used would represent an important step towards sustainable management.

Acknowledgements. J. B. C. Jackson, S. A. Sandin, J. Smith, L. Levin, P. Hastings, and T. Groves provided guidance from inception through submission. The comments of 4 anonymous reviewers were helpful in improving the manuscript. I am very grateful to my colleagues in Curaçao: F. Dilrosun, $\mathrm{H}$. Zimmerman, D. Kolunousky, M. Kolunousky, M. Vermeij, and G. van Buurt. C. Sprenger contributed invaluable statistical prowess. C. Dodge, K. Marhaver, K. Nichols, M. Goldstein, H. Czerski, C. Angioletti, and B. Neal provided diving assistance. This material is based upon work supported by the National Science Foundation under Grant No. 0333444 and a Graduate Research Fellowship. Additional funding was provided by Scripps Institution of Oceanography, Russ and Eloise Duff, Curaçao, Dienst Landbouw, Veeteelt \& Visserij (LVV), PADI Foundation, Easy Divers at Habitat Curaçao, Sunset Divers, and Foundation Reef Care Curaçao.

\section{LITERATURE CITED}

Alverson DL, Freeberg MH, Murawski SA, Pope JG (1994) A global assessment of fisheries bycatch and discards. FAO Fisheries Technical Paper. No. 339. FAO, Rome

Birkeland C, Dayton PK (2005) The importance in fishery management of leaving the big ones. Trends Ecol Evol 20: 356-358

Bohnsack JA, Sutherland DL, Harper DE, McClellan DB, Hulsbeck MW, Holt CM (1989) The effects of fish trap mesh size on reef fish catch off southeastern Florida. Mar Fish Rev 51:36-46

Bruggemann JH, van Kessel AM, van Rooij JM, Breeman AM (1996) Bioerosion and sediment ingestion by the Caribbean parrotfish Scarus vetula and Sparisoma viride: implications of fish size, feeding mode and habitat use. Mar Ecol Prog Ser 134:59-71

Burkepile DE, Hay ME (2008) Herbivore species richness and feeding complementarity affect community structure and function on a coral reef. Proc Natl Acad Sci USA 105: 16201-16206

- Chiappone M, White A, Swanson DW, Miller SL (2002) Occurrence and biological impacts of fishing gear and other marine debris in the Florida Keys. Mar Pollut Bull 44: 597-604

Cinner JE, McClanahan TR, Graham NAJ, Pratchett MS, Wilson SK, Raina J (2009) Gear-based fisheries management as a potential adaptive response to climate change and coral mortality. J Appl Ecol 46:724-732

- Cox TM, Lewison RL, Zydelis R, Crowder LB, Safina C, Read AJ (2007) Comparing effectiveness of experimental and implemented bycatch reduction measures: the ideal and the real. Conserv Biol 21:1155-1164

Dalzell P, Aini JW (1992) The performance of Antillean wire mesh fish traps set on coral reefs in northern Papua, New Guinea. Asian Fish Sci 5:89-102

Dilrosun F (2002) Progress report on Curaçao fishery monitoring program. FAO Fisheries R683 Suppl, p 9-20. Available at: http://www.fao.org/docrep/005/y4260e/y4260e05.htm

Ferry RE, Kohler CC (1987) Effects of trap fishing on fish populations inhabiting a fringing coral reef. N Am J Fish Manage 7:580-588

Froese R, Pauly D (2009) FishBase, available at www.fishbase.org (accessed August 22, 2009)

Garrison VH, Rogers CS, Beets J (1998) Of reef fishes, overfishing and in situ observations of fish traps in St. John, US Virgin Islands. Rev Biol Trop 46:41-59

> Garrison VH, Rogers CS, Beets J, Friedlander AM (2004) The habitats exploited and the species trapped in a Caribbean island trap fishery. Environ Biol Fishes 71:247-260

Gilbert M, Rasmussen JB, Kramer DL (2005) Estimating the density and biomass of moray eels (Muraenidae) using a modified visual census method for hole-dwelling reef fauna. Environ Biol Fishes 73:415-426

> Gobert B (1998) Density-dependent size selectivity in Antillean fish traps. Fish Res 38:159-167

Hardt MJ (2008) Lessons from the past: the collapse of Jamaican coral reefs. Fish Fish 10:1-16

> Hawkins JP, Roberts CM (2004) Effects of artisanal fishing on Caribbean coral reefs. Conserv Biol 18:215-226

> Hawkins J, Roberts C, Gell F, Dytham C (2007) Effects of trap fishing on reef fish communities. Aquat Conserv 17: $111-132$

Jackson JBC (1997) Reefs since Columbus. Coral Reefs 16: S23-S32

Knowlton N, Jackson JBC (2008) Shifting baselines, local impacts, and global change on coral reefs. PLoS Biol 6:215-220 
Lessios HA, Robertson DR, Cubit JD (1984) Spread of Diadema mass mortality through the Caribbean. Science 226:335-337

Mahon R, Hunte W (2001) Trap mesh selectivity and the management of reef fishes. Fish Fish 2:356-375

Mangi SC, Roberts CM (2006) Quantifying the environmental impacts of artisanal fishing gear on Kenya's coral reef ecosystems. Mar Pollut Bull 52:1646-1660

Mangi SC, Roberts CM, Rodwell LD (2007) Financial comparisons of fishing gear used in Kenya's coral reef lagoons. Ambio 36:671-676

McClanahan TR, Cinner JE (2008) A framework for adaptive gear and ecosystem-based management in the artisanal coral reef fishery of Papua New Guinea. Aquat Conserv 18:493-507

McClanahan TR, Mangi SC (2004) Gear-based management of a tropical artisanal fishery based on species selectivity and capture size. Fish Manag Ecol 11:51-60

McClanahan TR, Ruiz Sebastian C, Cinner J, Maina J, Wilson S, Graham NAJ (2008) Managing fishing gear to encourage ecosystem-based management of coral reefs fisheries. Proc 11th Int Coral Reef Symp, Ft. Lauderdale, FL

Munro JL (1974) Mode of operation of Antillean fish traps and relationships between ingress, escapement, catch and soak. J Cons Int Explor Mer 35:337-350

Munro JL (ed) (1983) The composition and magnitude of trap catches in Jamaican waters. In: Caribbean Coral Reef Fishery Resources. ICLARM, Manila, p 33-49

Munro JL, Reeson PH, Gaut VC (1971) Dynamic factors affecting the performance of the Antillean fish trap. Annu Proc Gulf Caribb Fish Inst 23:184-194

Munro JL, Sary Z, Gell FR (2003) Escape gaps: an option for the management of Caribbean trap fisheries. Annu Proc Gulf Caribb Fish Inst 54:28-40

Newman M, Paredes G, Sala E, Jackson J (2006) Structure of Caribbean coral reef communities across a large gradient of fish biomass. Ecol Lett 9:1216-1227

Editorial responsibility: Ivan Nagelkerken, Nijmegen, The Netherlands
Parsons GR, Thur SM (2008) Valuing changes in the quality of coral reef ecosystems: a stated preference study of SCUBA diving in the Bonaire National Marine Park. Environ Resour Econ 40:593-608

Pauly D, Christensen V, Dalsgaard J, Froese R, Torres F Jr (1998) Fishing down marine food webs. Science 279: 860-863

Robichaud D, Hunte W (1997) What factors explain reduced fishing power with increased mesh size of Antillean fish traps? Proc Gulf Caribb Fish Inst 49:273-279

> Robichaud D, Hunte W, Oxenford HA (1999) Effects of increased mesh size on catch and fishing power of coral reef fish traps. Fish Res 39:275-294

Robichaud D, Hunte W, Chapman MR (2000) Factors affecting the catchability of reef fishes in Antillean fish traps. Bull Mar Sci 67:831-844

Sandin SA, Sampaya EM, Vermeij MJA (2008) Coral reef fish and benthic community structure of Bonaire and Curaçao, Netherlands Antilles. Caribb J Sci 44:137-144

Sary Z, Oxenford HA, Woodley JD (1997) Effects of an increase in trap mesh size on an overexploited coral reef fishery at Discovery Bay, Jamaica. Mar Ecol Prog Ser 154: $107-120$

Sheridan P, Hill R, Matthews G, Appeldoorn R (2003) The effects of trap fishing in coralline habitats: What do we know? How do we learn more? Annu Proc Gulf Caribb Fish Inst 54:1-12

Stewart J (2007) By-catch reduction in wire-mesh fish traps. In: Kennelly SJ (ed) By-catch reduction in the world's fisheries. Springer, Dordrecht, p 75-93

> Wolff N, Grober-Dunsmore R, Rogers CS, Beets J (1999) Management implications of fish trap effectiveness in adjacent coral reef and gorgonian habitats. Environ Biol Fishes 55: $81-90$

Zaneveld JS (1961) The fishery resources and the fishery industries of the Netherlands Antilles. Annu Proc Gulf Caribb Fish Inst 14:137-171

Submitted: January 4, 2010; Accepted: August 4, 2010

Proofs received from author(s): September 10, 2010 